\title{
Incivility: The Moderating Effect of Hierarchical Status Does a Manager Inflict More Damage?
}

\author{
Yariv Itzkovich \\ Faculty of Management \\ Kinneret Academic College, Israel
}

Received: May 24, 2014

Accepted: June 24, 2014

Published: July 1, 2014

doi:10.5296/jmr.v6i3.5691

URL: http://dx.doi.org/10.5296/jmr.v6i3.5691

\begin{abstract}
Incivility is an expression of disregard toward others in a social interaction. The current study predicts that incivility will inflict more damage when perpetrated by higher status holders, for the intention to leave the organization, the possibility that the psychological contract will be violated and concerning organizational citizenship behaviors (OCB) that are expected to diminish.333 workers were sampled through a web based survey. Results showed that incivility can predict psychological contract violation and withdrawal intention. In addition, results showed that perceived incivility (i.e the perceived frequency with which incivility is experienced by its targets), was higher among those uncivil acts perpetrated by their managers compared to perceived incivility if perpetrated by a peer. Moreover, results suggested that while for some outcomes (i.e. OCB-O, withdrawal intentions, and psychological contract violation) managers inflict more damage as predicted, for OCB-I, the impact was greater when peers acted in an uncivil manner. Results as well as practical and theoretical implications are discussed.
\end{abstract}

Keywords: Incivility, Psychological contract violation, Withdrawal intentions, Organizational citizenship behavior 


\section{Introduction}

This study investigates whether perception of incivility (i.e the perceived frequency with which incivility is experienced by its targets) interacts with the perpetrator's status in the outcome of the encounter. Until now, research on incivility has found that power is a built-in parameter of the equation. The perpetrator holds a higher hierarchical status than the victim (Pearson, Andersson, \& Porath, 2000; Phillips \& Smith, 2003) mainly because powerful perpetrators can easily victimize powerless victims. The latter will prefer to avoid confronting higher status figures since by confrontation, they invite more power that could be asserted over them (Cortina \& Magley, 2003; Pearson, Andersson, \& Wegner, 2001; Porath, Overbeck, \& Pearson, 2008). This study aims to show not only that the perpetrator holds a higher status ,but also that the damage inflicted by managers is greater than that inflicted by the victim's peers. Specifically, in the current study, the interaction effect of the perpetrator's hierarchical status and incivility will be studied for OCB, withdrawal intentions and psychological contract violation.

\section{Literature Review}

\section{1. Incivility}

Andersson and Pearson (1999) defined incivility as

...acting with disregard for others in the workplace in violation of workplace norms of respect (p. 454).

While norms of mutual respect, courtesy, politeness and helping both the organization and its members are expressions of ideal moral standards which support the psychological and social context of work environments (Hayes, 2005, Organ, 1988; Organ, 1997 Phillips \& Smith, 2003; Motowildo, Borman, \& Schmit, 1997), disrespect, rudeness and lack of consideration are the cornerstones of incivility (Andersson \& Pearson, 1999; Pearson \& Porath, 2005; Porth \& Erez, 2005). Compared to aggressive and intense behaviors, incivility is a milder form of misconduct characterized by an ambiguous intent by perpetrators to harm their victims (Andersson \& Pearson, 1999). Moreover, incivility is more prevalent than other behaviors such as bullying or aggression, as has been reported by Pearson, Andersson, and Porath (2000), as well as by Pearson and Porath (2005).

Like bullying and aggression, incivility is a deviant interpersonal behavior according to Robinsson's and Bennett typology (1995). However, incivility differs from bullying and aggression in intensity. On a theoretical scale of intensity, incivility is at the lowest continuum of the scale while aggression is at the highest. Moreover, while the intention to harm the victim in bullying and aggression is clear (Anderson \& Bushman, 2002; Vandekerckhove \& Commers, 2003), incivility is characterised by an ambiguous intent to harm the victim (Cortina, Magley, Williams, \& Langhout, 2001).

Although not intentional, uncivil acts inflict harm on their victims. These consequences will be examined here through perceived psychological contract violation ,OCB, and withdrawal 
intentions.

\subsection{Psychological contract violation}

The psychological contract is one of the fundamental theoretical constructs in the organizational behavior literature. The construct was prominent in OB research during the late 80 's, and later retained prominence mainly due to Rousseau's contribution to its definition and to the understanding of its antecedents and implications (Robinson \& Rousseau, 1994; Rousseau, 1989; Rousseau, 1995). Rousseau called it the subjective perception of entitlements and obligations that are based on perceived promises (Rousseau, 1989; Rousseau, 1995). Although at first it was defined as the mutual output of joint discussion between the employee and the organization (Kotter, 1973), Rousseau emphasized that there is no need for mutuality or solid obligations in order to establish, maintain or breach a psychological contract (Rousseau, 1989; Rousseau, 1995). As the different sides of the contract do not regularly coordinate expectations, contracts are commonly violated. As evidence, Robinson and Rousseau (1994) reported that up to $54.8 \%$ of the participants in their study experienced violation of their contract.

Contract violation develops when the employee feels that one or more of his perceived entitlements is not fulfilled. The ensuing feelings of betrayed and anger might develop into retaliatory behavior. In some cases, employees will leave the organization, while in others, they will steal, damage property or search for some other destructive retaliatory response (Morison \& Robinson, 1997). While early studies emphasized the tangible facets of psychological contracts, recent studies have emphasize their social facet by stressing that interpersonal relationships are mandatory elements (Coyle-Shapiro, 2002). Consideration of relationships as part of the entitlements facet of the psychological contract implies that damaged relations, as manifested through incivility, will violate the contract. This is especially so in that the quality of interpersonal interactions is significant as an economic transaction in relation to the emotional and behavioral reactions aroused when the interaction is destructive (Stecher \& Rosse, 2005). Following Rousseau (1995), it is obvious that in some cases of breach of contract, when the victim can differentiate between his experience and the responsibility of the offender for his experience (as in the case of economic crises that lead to salary cuts), the probability that the contract will be violated is reduced. Yet in the case of incivility, there is little option to differentiate the experience of the victim from the responsibility of the offender, as in the majority of incivility incidents, the perpetrator is the direct manager. This is also the reason that in the case of incivility, managerial support is unavailable, but if present, managerial support can reduce the experience of losing (Chrobot-Mason, 2003). On this basis, the first hypothesis is advanced.

Hypothesis 1: Perceived incivility will have a direct positive effect on psychological contract violation.

When incivility occurs, psychological contract violations are not the only price organizations and individuals are obliged to pay. Incivilities can damage organizational citizenship behaviors as well. 


\subsection{Organizational Citizenship Behavior}

Initially Organ (1988) defined OCB as

...individual behavior that is discretionary not directly or explicitly recognized by the formal reward system and in the aggregate promotes the effective functioning of the organization. By discretionary we mean that the behavior is not enforceable requirement of the role or job description, that is, the clearly specifiable terms of the person's employment contract with the organization. The behavior is rather a matter of personal choice, such that its omission is not generally understood as punishable (pp. 4).

Organ (1988) introduced five categories of OCB which were later grouped by Williams and Anderson ( 1991) into two categories: OCB-O, behaviors directed to benefit the organization and OCB- I, directed to benefit the individuals. Recently, Organ gave OCB a more generic definition and defined OCB as a behavior that supports the psychological and social environment in which the production activity take place (Organ, 1997). By doing so he overcame the difficulty of deciding whether the citizenship behavior is part of the job definition or if it is rewarded directly by the organization reward system, as suggested in his initial definition.

The roots of Organ's definitions lie in the foundations of social exchange theory (Blau, 1964) and in Gouldner's (1960) reciprocity model. Together the two concepts support the notion that employees will express positive voluntary behaviors in return for social support, yet according to the negative reciprocity model (Helm, Bonoma, \& Tedeschi, 1972), they will avoid such positivism in response to unsupportive social conditions. It can therefore be hypothesized that incivility which represents negative social exchange will lead to reduced OCB behaviors.

Hypothesis 2: Perceived incivility will have a direct negative effect on OCB behaviors.

In addition, according to the reciprocity model and social exchange theory (Blau, 1964; Gouldner, 1960), people tend to associate with those that respect them and arouse their positive emotions. Conversely, a discourteous atmosphere will arouse frustration that in turn will elicit psychological withdrawal intentions. With no solution to their frustration, victims will physically withdraw from the relationship (Pearson et al., 2001). Empirical data shows that half of incivility victims waste time worrying about what will happen, while others consider leaving the organization in order to avoid future unpleasant incidents (Pearson \& Porath, 2005). On the basis of the above, the next hypothesis can be advanced.

Hypothesis 3: Perceived incivility will have a direct positive effect on withdrawal intentions.

The theoretical background to the notion that the perpetrator's status can moderate the relationship between incivility perception and its outcomes (i.e. psychological contract violation, OCB behaviors and withdrawal intentions) can be found in Montgomery, Kane \& Vance (2004). The researchers recommend investigating the moderating effect of status on the relation between rude behaviors and disempowerment. They assume that the higher the status of the perpetrator, the greater the damage that he can inflict on the victim's 
empowerment perceptions. Despite sufficient theoretical background, the moderating effect of the perpetrator's status on the relationship between incivility and its outcomes was overlooked in the early research on incivility. However recent studies have investigated the notion that higher status perpetrators inflict more damage than lower status ones. Cortina and Magley (2003) showed that the higher the status of the perpetrator is, the more the victims will experience social and work retaliation victimization. Others found that incivility perpetrated by hospital managers inflicts more damage than incivility perpetrated by patients (Scott \& Donna, 2008). In accordance, it was reported by Caza and Cortina (2007) that faculty incivility inflicts more damage than student incivilities. In addition, Porath et al. (2008) showed that the perpetrator's status counts when deciding whether to fight or flee. In light of the above, this study hypothesizes the following.

\section{Hypotheses 4-6:}

4. Perpetrator status will moderate the relations between Perceived incivility and OCB.

5. Perpetrator status will moderate the relations between Perceived incivility and withdrawal intentions.

6. Perpetrator status will moderate the relations between Perceived incivility and perceptions of psychological contract violation.

\section{Methodology}

A web based survey was administered to approximately 1500 MBA students in one of the biggest universities in Israel. 195 questionnaires were collected from this group. The second half of the sample (153 questionnaires) was obtained from a group of 100 social friends each of whom was asked by email followed by a telephone call, to distribute the web link to an additional 10 friends. It is estimated that 750 working people received the link. 153 questionnaires were collected using this method. This method of sampling allows on the one hand, getting sufficient variance concerning the research variables, and on the other, it affords participants sufficient anonymity for answering sensitive questions.

Each participant could complete the questionnaire in his or her own time from any computer without identification. In total, 333 questionnaires contained usable data $(\mathrm{N}=333)$.

Average respondent age was 35.5 with organizational tenure of 6.75 years. 55.6\% were woman, $65 \%$ were married, $93 \%$ held a BA or MBA degree, $40 \%$ worked in the private sector and the rest in the public sector.

\subsection{Measures}

\subsubsection{Incivility}

The work incivility scale (WIS) developed by Cortina et al. (2001) was used in order to test the victimization perception. The measure consists of seven items asking the respondents to indicate how frequently someone at work had acted in an uncivil manner toward them over the previous year. Answers ranged from $1=$ never to $5=$ most of the time. After the fifth question was rephrased and the seventh (i.e., made unwanted attempts to draw you into a 
discussion of personal matters) deleted due to lack of consistency with the rest, as well having as low construct validity according to two content experts, the final, $\alpha$ score was 0.897 for the six-item scale.

\subsubsection{Psychological contract violation}

The scale was developed based on Robinson and Rousseau's (1994) findings and was validated through a pilot test. 4 questions on a 5-point Likert scale were used to measure perceived psychological contract violation. Respondents were asked to indicate to what extent their employers violated their obligations to them. Answers ranged from $1=$ never to 5 - = very often. Cronbach's $\alpha$ for the scale was 0.906 .

\subsubsection{OCB}

Williams and Anderson's (1991) scale for measuring OCB-I and OCB-O was translated into Hebrew and used in a Likert scale ranging between $1=$ not at all to $5=$ very much. The original scale consisted of 14 questions. During the pilot stage, the OCB-O measurement ( 7 questions out of the 14) was found to be insufficiently reliable $(\alpha=0.3)$, therefore only the OCB-I scale was used ( $\alpha$ was 0.796.$)$

\subsubsection{Withdrawal intentions}

6 questions were used in order to measure intention to leave both the organization and job, based on Carmeli (2005) and the original scale of Hom, Caranikas-Walker, Prussia and Griffeth (1992). The final scale consists of 6 questions on a Likert scale ranging from $1=$ most probably to $5=$ not at all. The $\alpha$ score was 0.935 .

\subsubsection{Critical incidents}

Three critical incidents were developed in order to represent the core characteristics of incivility in Israeli culture. Pen and paper questionnaires were given to a group of ten workers in a large high-tech company in Israel. Participants were asked to nominate two cases of incivilities they anticipated or had witnessed, after they received a short definition of the construct. In addition, one focus group and ten short interviews were conducted in the same company. Out of these, twenty two clear sentences representing manifestations of incivility were selected and given to three independent groups of students who were asked to identify the sentences that to the best of their understanding represented incivility. Only sentences that were chosen by the three groups were considered in the next phase. In another undergraduate class, significant themes were taken out of the chosen sentences. At this stage, three dimensions of incivility were identified - ignoring an employee (on a professional basis), condescension and belittlement. In light of these, three scenarios were developed on the basis of real scenarios that had been given in previous stages. The three scenarios were given to twenty evaluators in order to make sure they represented the three main types identified earlier. Four questions constituted the final scale of each one of the three scenarios, which asked respondents to estimate how the victim in the scenario would react and/or feel with regards to OCB-O/I, psychological contract violation and withdrawal intentions. In two out of the three scenarios, the manager played the perpetrating figure whereas in the third scenario, 
a peer did. In all three scenarios, the incivility level was defined as frequent. For Scenario 1, Cronbach's $\alpha$ was 0.895 , for scenario 2 it was 0.795 , and for scenario 3 it was 0.786 .

\section{Results}

Table 1. presents the mean correlations and standard deviations of all research variables. Table 1 shows a significant positive correlation between incivility and psychological contract violation $(\mathrm{r}=0.513, \mathrm{p}<0.01)$ as well as a a significant positive correlation between incivility and withdrawal intentions $(\mathrm{r}=0.428, \mathrm{p}<0.01)$, yet it failed to indicate a significant correlation between incivility and OCB.

Table 1. Descriptive Statistics and correlation among study variables

\begin{tabular}{|c|c|c|c|c|c|c|}
\hline Variable & Mean & S.D & $\mathbf{1}$ & $\mathbf{2}$ & $\mathbf{3}$ & $\mathbf{4}$ \\
\hline & & & & & & \\
\hline 1. contract violation & 2.39 & 1.098 & - & $0.426^{* *}$ & -0.075 & $0.513^{* *}$ \\
\hline 2. withdrawal intentions & 2.01 & 1.129 & & - & -0.048 & $0.428^{* *}$ \\
\hline 3. OCB & 3.73 & 0.650 & & & - & -0.063 \\
\hline 4. Incivility Perception & 1.87 & 0.824 & & & & - \\
\hline
\end{tabular}

$\mathrm{N}=333 \quad * * \mathrm{P}<.01 * \mathrm{P}<0.05$

Results of a hierarchical regression showed that incivility can predict $26.7 \%$ of the variance for psychological contract violation, $\mathrm{F}(4,328)=29.846, p<0.05$, when gender tenure and education were controlled. In addition, results showed that incivility can predict $20.2 \%$ of the variance for withdrawal intentions, $\mathrm{F}(4,328)=20.719, p<0.05$, when gender education and tenure were controlled. However, regression failed to find a direct effect between incivility and OCB. Moreover, the interaction of incivility perception and perpetrator's status for each of the independent variables was also not significant.

In order to test differences between the means of all three groups represented through the three scenarios, paired sample $t$-tests were conducted. Results of the $t$-tests were significant: $t(332)=16.131 ; t(332)=-13.03 ; \quad t(332)=-4.655 ;$ in each case, $p<0.01$.Specifically, when the perpetrator was a manager, the means of the two scenarios were $(M=2.81, S D=0.881)$ and $(M=3.39, S D=0.787)$, whereas when incivility was perpetrated by a peer the mean was lower $(M=2.57, S D=0.912)$.

Although not predicted for a comparison of incivility perception incivility (i.e the perceived frequency with which incivility is experienced by its targets) between two distinct groups of perpetrators, (i.e. peer and manager), an independent t-test was significant: $t(165.827)=3.559$, $p<0.01$. The mean of incivility perception was $(M=1.79, S D=0.622)$ when the perpetrator 
was a peer, and $(M=2.23, S D=0.991)$ when the perpetrator was a manager.

In addition, while not predicted, it was found that out of the four questions in each of the scenario scales, only the one asking the participant if the victim of incivility (in the scenario) would help others less, yielded a bigger and significant difference, $t(332)=6.768, p<0.01$ when the perpetrator in the scenario was a peer. The mean when the perpetrator in the scenario was a peer $(M=2.94, S D=1.190)$, was significantly higher compared to the first scenario in which the perpetrator was a manager $(M=2.48, S D=1.028)$ and higher although not significant comparing to the second scenario in which the perpetrator was a manager, $(M=2.87, S D=1.057)$ while all the other three questions in the scale yielded higher means when the perpetrator was a manager.

\section{Discussion}

This study investigated the consequences of uncivil behavior as well as the interaction of the perpetrator's status with incivility perception. It was predicted that psychological contract violation and withdrawal intentions would increase during an uncivil interaction, that OCB would decrease when facing such an uncivil interaction, and that perpetrator status would interact with perceived incivility for the three outcomes.

Results indicate that psychological contract violation can be predicted by incivility perception. This reflects the fact that relationships are a built-in parameter of the contract and are important for its maintenance. Once these relationships are damaged, the contract is violated. The finding with regard to withdrawal intentions indicates that individuals who anticipate high levels of incivility at work are willing to withdraw from it.

There was no direct effect between incivility and OCB. One explanation might be that participants were asked about OCB-I but not OCB -O. As most incivilities are top - down processes and not horizontal (i.e. conducted by peers), there is less incentive for the victim to reduce his helpful behaviors toward others who have not hurt him, as his victimization stems from managerial figures that in turn represent the organization.

The research model suggests that the relationship between incivility perception and the dependent variables is moderated by the hierarchial status of the perpetrator. A hierarchial regression did not yield a significant moderating effect of prepetrator's hierarchial status on the relationship between incivility and the dependent variables, yet paired sample $t$-tests showed significant differences between the means of the three scenarios which differed mainly according to the perpetrator's status. It was found that the reactions of the participants to the questions in the scenario were stronger when the perpetrator was a manager. This finding indicates that the higher the status, the greater the damage, yet in order to investigate the moderating effect of status through the scenarios, the scenarios should demonstrate low levels of incivility as well ( in all three scenarios the level of incivility was fixed and high). An interesting finding with regard to the influence of perpetrator's status emerged when each of the 4 questions that constitute the scenario's scale was investigated separately. In all three questions concerning OCB- $\mathrm{O}^{1}$, psychological contract and widthrawal

\footnotetext{
${ }^{1}$ Only part of the scenario's OCB-O was tested.
} 
intentions, the higher the status of the perpetrator, the greater the damage inflicted, yet with regards to OCB-I, the damage was bigger when a peer perpetrated the incivility. An explanation for this could be that when a peer perpetrates an uncivil act, the motivation to help peers perceived as harmful is reduced, while at the same time the organization is perceived as less accountable for the harmful act. In light of the above, there is a possibility that the direction of the interaction between the perpetrator's status and incivility is mutative and depends on the variables tested.

Moreover, when trying to understand why the moderating effect was not found in the regression analysis, it was found that the incivility perception itself was reported more frequently when a manager perpetrated the uncivil act. There are two possible explanations for this difference. The first explanation is objective and relies on power differences. A manager might feel more protected due to his social position within the organization, and allow himself to act in an uncivil manner more frequently toward the same victim. This explanation raises the question of the unintential characteristics of incivility, since, if this assumption is correct, there is a clear instrumental calculation in such behavior. Another explanation for the above result might be more perceptual and therefore subjective. When participants are asked how often someone at work has ignored them on a professional basis (as an example from the WIS scale), the participant has a clear image of the perpetrator's identity in his mind while answering, yet he does not accurately recall the frequency of the uncivil encounters during a period of half to one year. As his relationship with his managers will influence his future at work, any uncivil encounter with his manager will be recalled from memory better than any encounter with his peers. In both cases the WIS scale might weigh not only the intensity of incivility but also the identity of the perpetrator, which might bias the results. In light of this, it is also less likely that the effect of the perpetrator's hierarchial status will be the moderator of the relationship between incivility and its outcomes, as it already embedded in incivility perception itself. Yet, in the scenarios it was different. In all three scenarios the level of incivility was fixed and intense. The only place participants could react to the difference in perpetrator's status was through the victim's reactions to incivility. In this manner, the effect of the perpetrator's status might be distilled.

When compared to other empirical data, it can be noted that this study's findings reinforces the notion of Coyle- Shapiro (2002) that relationships are a built-in parameter in the contract and once those are broken, the contract is breached as well. This notion is strengthened in light of other data claiming that the interactional justice (represented though civil relationships) is significant as distributive justice concerning the emotional vigilance aroused when it is not maintained (Seter, 2001).

In addition in the current study, incivility was found to be a valid variable for predicting withdrawal intentions. These findings are in line with previous data (e.g Cortina et al., 2001; Cortina and Magley, 2003). However, the research failed to support the prediction that OCB behaviors would be reduced as a result of incivility. Nevertheless, in light of other studies (Pearson et al., 2000; Pearson et al., 2001; Porth \& Erez, 2005), the relationship between incivility and OCB behaviors should be further investigated. 
This study contributes to the literature in a number of ways. To date no research has demonstrated a correlation between psychological contract violation and incivility. Such a relationship can widen the conceptual framework of incivility, as the psychological contract violation in turn can lead to more destructive behaviors as predicted in the EVLN model (Farrell \& Rusbult, 1992; Morison \& Robinson, 1997 ;Rousseau, 1995). To date, these destructive behaviors have been overlooked in the literature of incivility. Another contribution lies in the present findings, which suggest that the notion that the higher the perpetrator's status is, the greater the impact of his behavior will be, might not be accurate. According to this study's findings, it is more dimension dependent. To date the research has overlooked this option. The last contribution lies in the development of three scenarios that can be used to measure incivility through another instument different from the WIS scale.

As with every study, this has a number of limitations. The first lies in the fact that the research used a cross sectional design. This might imply that the regression presented in this study could have gone the other way, and that psychological contract violation for instance, would elicit uncivil behavior, as it may damage the relationship strength as Rousseau (1995) noted in her psychological contract violation model. An additional limitation lies in the content of the sample. On the one hand, the sampling method did not focus on specific organizations or sampling methods that would enable generalization of the results, yet on the other hand, the sampling method allowed participants the confidentiality they needed in order to safely answer sensitive questions.

\section{Conclusion}

This study attempts to investigate whether perception of incivility interacts with the perpetrator's status in the outcome of the encounter. Results showed that incivility can predict psychological contract violation and withdrawal intention and that perceived incivility (i.e. the perceived frequency with which incivility is experienced by its targets), was higher among those uncivil acts perpetrated by their managers compared to perceived incivility if perpetrated by a peer. This finding implies that a perpetrator's power is a built-in parameter in the equation of incivility. Yet my results suggest that the relationship between the power of the perpetrator and the perception of the victim are more complex than predicted. While for most outcomes (i.e. OCB-O, withdrawal intentions, and psychological contract violation) managers inflicted more damage as predicted, for OCB-I, the impact was greater when peers acted in an uncivil manner. In light of such diverse results, the moderating effect of a perpetrator's power in the relationship between incivility and its outcomes should be investigated further. In addition, the top-down pattern of most uncivil encounters raises doubt about the unintentional characteristics of incivility. Since victims of uncivil acts are mostly located at the lower end of the organizational hierarchy, while perpetrators are more likely to occupy higher positions, there may well be an instrumental calculation while perpetrating an uncivil act. The perpetrator may calculate the risks embedded in perpetrating the incivility and therefore chooses targets which will minimize its risks. Such an instrumental approach can explain the top -down pattern of incivility yet at the same time it questions the ambiguity of intention while perpetrating uncivil acts. To summarise, I suggest that when status differences on incivility outcomes are investigated in the future, it might be useful to use 
scenarios as an indirect method that may distill the effect of status differences on incivility outcomes. To date, such a method has not been common in the incivility research.

\section{References}

Anderson, C. A., \& Bushman, B. J. (2002).Human Aggression. Annual Review of Psychology, 53, 27-51. http://dx.doi.org/10.1146/annurev.psych.53.100901.135231

Andersson, L., \& Pearson, C. M. (1999). Tit for tat? The spiraling effect of incivility in the workplace. Academy of Management Review, 24(3), 452-471. http://dx.doi.org/10.5465/AMR.1999.2202131

Blau, P.M. (1964). Exchange and power in social life. New York: Wiley.

Carmeli, A. (2005). The relationship between organizational culture and withdrawal intentions and behavior. International Journal of Manpower, 26(2), 177-196. http://dx.doi.org/10.1108/01437720510597667

Caza, B., \& Cortina, M. (2007). From insult to injury: Explaining the impact of incivility. Basic and Applied Social Psychology, 29(4), 335-350. http://dx.doi.org/10.1080/01973530701665108

Chrobot-Mason, D. (2003). Keeping the promise: Psychological contract violations for minority employees. Journal of Managerial Psychology, 18(1), 22-45. http://dx.doi.org/10.1108/02683940310459574

Cortina, L.M., \& Magley, V. J. (2003). Raising voice, risking retaliation: Events following mistreatment in the workplace. Journal of Occupational Health Psychology, 8(4), 247-265. http://dx.doi.org/10.1037/1076-8998.8.4.247

Cortina, L. M., Magley, V. J., Williams, J. H., \& Langhout, R. D. (2001). Incivility in the workplace: Incidence and impact. Journal of Occupational Health Psychology, 6(1), 64-80. http://dx.doi.org/10.1037/1076-8998.6.1.64

Coyle-Shapiro, J.M. (2002). A psychological contract perspective on organizational citizenship behavior. Journal of Organizational Behavior, 23(8), 927-946. http://dx.doi.org/10.1002/job.173

Farrell, D., \& Rusbult, C. (1992). Exploring the exit voice loyalty and neglect typology: The influence on job satisfaction quality of alternatives and investment size. Employee Responsibilities and Rights Journal, 5(3), 201-218. http://dx.doi.org/10.1007/BF01385048

Gouldner, A. (1960). The norm of reciprocity: A preliminary statement. American Sociological Review, 25 (2), 161-178. http://dx.doi.org/10.2307/2092623

Hayes, N. (2005). Managing Teams: A Strategy for Success. London, UK: International Thomson Business Press.

Helm, B., Bonoma, T., \& Tedeschi, J. (1972). Reciprocity for harm done. Journal of Social Psychology, 87 (1), 89-98. http://dx.doi.org/10.1080/00224545.1972.9918651 
Hom, V., Caranikas-Walker, F., Prussia, E., \& Griffeth, W. (1992). A meta analytical structural equations analysis of a model of employee turnover. Journal of Applied Psychology, 77(6), 890-909. http://dx.doi.org/10.1037/0021-9010.77.6.890

Kotter, J. (1973). The psychological contract: Managing the joining-up process. California Management Review, 15(3), 91-99. http://dx.doi.org/10.2307/41164442

Montgomery, K., Kane, K., \& Vance, M. (2004). Accounting for differences in norms of respect: A study of assessments of incivility through the lenses of race and gender. Group $\begin{array}{llll}\text { and } \quad \text { Organization 248-263. } & \text { Management, }\end{array}$ http://dx.doi.org/10.1177/1059601103252105

Morrison, L., \& Robinson, S. (1997). When employees feel betrayed:A model of how psychological contract violation develops. Academy of Management Review, 22 (1), 226-256. http://dx.doi.org/10.5465/AMR.1997.9707180265

Motowildo, S. J., Borman, W. C., \& Schmit, M. J. (1997). A theory of individual differences in task and contextual performance. Human Performance, 10(2), 71-83. http://dx.doi.org/10.1207/s15327043hup1002_1

Organ, D W. (1988). Organizational citizenship behavior: The good soldier syndrome. Toronto: Lexington Books.

Organ, D. W. (1997). Organizational citizenship behavior: It's construct clean up time. Human Performance, 10(2), 85-97. http://dx.doi.org/10.1207/s15327043hup1002_2

Pearson, C. M., Andersson, L. M., \& Wegner, J. W. (2001). When workers flout convention: A study of workplace incivility. Human Relations, 54(11), 1387-1419. http://dx.doi.org/10.1177/00187267015411001

Pearson, C. M., Andersson, L.M., \& Porath, C. (2000). Assessing and attacking workplace $\begin{array}{llll}\text { incivility. Organizational } & \text { Dynamics, } & \text { 29(2), }\end{array}$ http://dx.doi.org/10.1016/S0090-2616(00)00019-X

Pearson, C.M., \& Porath, C.L. (2005). On the nature, consequences and remedies of workplace incivility:No time for "nice"? Think again. Academy of Management Executive, 19(1), 7-18.

Phillips, T., \& Smith, P. (2003). Everyday incivility: Towards a benchmark. Sociological Review,51(1) 85-108.

Porath, C., Overbeck, R., \& Pearson, C. (2008). Picking up the gauntlet: How individuals respond to status challenges. Journal of Applied Social Psychology, 38(7), 1945-1980. http://dx.doi.org/10.1111/j.1559-1816.2008.00375.x

Porath, C., \& Erez, A. (2005,August). Does incivility really matter? The effects of incivility on performance motivation creativity helpfulness and disfunctional behavior. Academy of Management Seminar, Honolulu. 


\section{Macrothink}

Journal of Management Research ISSN 1941-899X 2014, Vol. 6, No. 3

Robinson, S., \& Rousseau, D. (1994). Violating the psychological contract: Not the exception but the norm. Journal of Organizational Behavior, 15(3), 245-249. http://dx.doi.org/10.1002/job.4030150306

Robinsson, S., \& Bennett, R. (1995). A typology of deviant workplace behavior: A multidimensional scaling study. Academy of Management Journal, 38(2), 555-572. http://dx.doi.org/10.2307/256693

Rousseau, D. (1989). Psychological and implied contracts in organizations. Employee Responsibility and Rights Journal, 2, 121-139. http://dx.doi.org/10.1007/BF01384942

Rousseau, D. (1995). Psychological contracts in organizations. London: Sage Publications.

Scott, H., \& Donna, G. (2008). Workplace incivility and productivity losses among direct care staff. AAOHN Journal, 56(4), 168.

Seter, O. (2001). Entitlements and obligations: Psychological contracts of organizational members. Ph.D. Dissertation, Tel Aviv: Tel Aviv University. (In Hebrew).

Stecher, M., \& Rosse, J. (2005). The distributive side of interactional justice: The effects of interpersonal treatment on emotional arousal

. Journal of Managerial Issues, 17(2), 229-246.

Vandekerckhove, W., \& Commers, R. M. (2003). Downward workplace mobbing: A sign of the times? Journal of Business Ethics, 45(1), 41-50.

Williams, L., \& Anderson, S. (1991). Job satisfaction and organizational commitment as predictors of organizational citizenship and in-role behaviors. Journal of Management, 17(3), 601-617. http://dx.doi.org/10.1177/014920639101700305

\section{Copyright Disclaimer}

Copyright for this article is retained by the author(s), with first publication rights granted to the journal.

This is an open-access article distributed under the terms and conditions of the Creative Commons Attribution license (http://creativecommons.org/licenses/by/3.0/). 